\title{
Efficacy and safety of calcitonin-gene- related peptide binding monoclonal antibodies for the preventive treatment of episodic migraine - an updated systematic review and meta-analysis
}

\author{
Hong Deng, Gai-gai Li*, Hao Nie, Yang-yang Feng, Guang-yu Guo, Wen-liang Guo and Zhou-ping Tang*
}

\begin{abstract}
Background: Migraine is one of the most common neurological disorders that leads to disabilities. However, the conventional drug therapy for migraine might be unsatisfactory at times. Therefore, this meta-analysis aimed to evaluate the efficacy and safety of calcitonin-gene-related peptide binding monoclonal antibody (CGRP mAb) for the preventive treatment of episodic migraine, and provide high-quality clinical evidence for migraine therapy.

Methods: A systematic electronic database search was conducted to identify the potentially relevant studies. Two independent authors performed data extraction and quality appraisal. Mean difference (MD) and risk ratio (RR) were pooled for continuous and dichotomous data, respectively. The significance levels, weighted effect sizes and homogeneity of variance were calculated.

Results: Eleven high-quality randomized control trials that collectively included 4402 patients were included in this meta-analysis. Compared to placebo group, CGRP mAb therapy resulted in a reduction of monthly migraine days [weighted mean difference (WMD) $=-1.44,95 \% \mathrm{Cl}=(-1.68,-1.19)]$ and acute migraine-specific medication days $[\mathrm{WMD}=-1.28,95 \% \mathrm{Cl}=(-1.66,-0.90)]$, with an improvement in $50 \%$ responder rate $[\mathrm{RR}=1.51,95 \% \mathrm{Cl}=(1.37,1.66)]$. In addition, the adverse events (AEs) and treatment withdrawal rates due to AEs were not significantly different between CGRP mAb and placebo groups. Similar efficacy and safety results were obtained for erenumab, fremanezumab, and galcanezumab in subgroup analysis.

Conclusions: The current body of evidence reveals that CGRP mAb is an effective and safe preventive treatment for episodic migraine.
\end{abstract}

Keywords: Calcitonin gene-related peptide monoclonal antibody, Episodic migraine, Efficacy, Safety, Meta-analysis

\section{Background}

Migraine is one of the most common neurological diseases characterized by unilateral localization, pulsating quality, moderate to severe pain intensity and avoidance of movement [1, 2]. According to the 2013 Global Burden of Disease Study, over half of all years lost to disability resulting from neurological disorders are attributed to migraine [3-5]. Episodic migraine is the most

\footnotetext{
* Correspondence: Igghuster@163.com; ddjtzp@163.com

Department of Neurology, Tongji Hospital, Tongji Medical college, Huazhong University of Science and Technology, Wuhan 430030, China
}

common form of migraine, defined as occurring on fewer than 15 days per month in accordance with the third version of the International Classification of Headache Disorders (ICHD-3) edited by the International Headache Society (IHS) [6, 7]. It can be further subdivided into high-frequency episodic migraine (HFEM) and low-frequency episodic migraine (LFEM) based on frequency. Previous studies usually used frequencies from 8 to 14 and 10 to 14 migraine headache days (MHDs) per month to define HFEM [8]. As for when to start preventive treatment, there is no certain evidence

(c) The Author(s). 2020 Open Access This article is distributed under the terms of the Creative Commons Attribution 4.0 International License (http://creativecommons.org/licenses/by/4.0/), which permits unrestricted use, distribution, and 
now, only based on rules of thumb or expert opinions [9-11]. It may depend on a number of factors, including attack frequency and severity, responsiveness to medications for acute migraine, and coexisting conditions [9]. It's generally believed that preventive therapy should be initiated if migraine occurs at least once per week or on 4 or more days per month [9]. However, due to the lack of efficacy and intolerable side effects of available conventional preventive therapies, the management of patients with migraine might be unsatisfactory sometimes. Thus, novel effective drugs with good tolerability, few side effects and high retention rates are needed for episodic migraineurs.

Calcitonin gene-related peptide (CGRP) has been found to play an important role in the pathophysiology of migraine via nociceptive mechanisms in the trigeminovascular system [12]. At present, there are four monoclonal antibodies (mAbs) targeting the CGRP, namely, eptinezumab (ALD403), fremanezumab (TEV-48125; previously known as LBR-101 or RN-307), galcanezumab (LY2951742) and erenumab (AMG334). The former three are humanized mAbs that potently and selectively bind to CGRP, while the latter one is the only monoclonal antibody that targets CGRP receptor instead of CGRP ligand. All of them have been studied in clinical trials for the preventive treatment of episodic migraine.

Although a previous meta-analysis has assessed the efficacy and safety of CGRP mAbs for episodic migraine [13], several new high-quality randomized control trials (RCTs) are not included in the published meta-analysis [14-18]. Therefore, we conducted an updated metaanalysis to comprehensively investigated the efficacy and safety of CGRP mAbs for the preventive treatment of episodic migraine.

\section{Methods}

\section{Literature search}

This meta-analysis was conducted according to the recommendations of the Preferred Reporting Items for Systematic Reviews and Meta-Analyses (PRISMA) statement. We systematically searched MEDLINE, EMBASE, the Cochrane Controlled Trials Register (CENTRAL), and Web of Science (from inception to 9th, March,2019). The search keywords included ("eptinezumab" OR "ALD403" OR "fremanezumab”OR “TEV-48125” OR "galcanezumab" OR "LY2951742" OR "erenumab" OR “AMG334”) AND "episodic migraine". There were no area limitation or language restriction. To identify other potentially relevant studies, the reference lists of the retrieved articles were searched manually.

\section{Study selection}

Studies were included in this meta-analysis if they met the following criteria. (i) Randomized, double-blinded, placebo-controlled, parallel-group studies with experimental and control groups receiving CGRP mAbs and matched placebo, respectively. (ii) Adults aged $\geq 18$ years, regardless of gender or ethnicity. (iii) Subjects diagnosed with episodic migraine according to the International Classification of Headache Disorders III (ICHD-III) for at least 1 year prior to enrollment [19]. (iv) Studies reported at least one of the following outcomes: the decreased number of monthly migraine days, $\geq 50 \%$ reduction from baseline in the mean number of migraine days per month, monthly acute migraine-specific medication prescribed from baseline to endpoint, and adverse events (AEs).

Exclusion criteria were: (i) non-human studies; (ii) case series or case reports; (iii) review articles, meta-analysis or letters to the editor; and (iv) multiple reports from the same cohort.

One author (HD) performed initial eligibility screening by assessing the titles and abstracts of all retrieved articles. Following initial screening, 2 authors (HD and G-GL) independently reviewed the full-text copies of potentially eligible articles. Disagreements were resolved through discussion.

\section{Outcome measurement}

The primary efficacy outcome measures were the changes in the number of monthly migraine days from baseline to endpoint and monthly acute migraine-specific medication days. We extracted the data at weeks $9-12$ in most time. If the data was not available, those at week 24 were used instead $[17,18]$. The achievement of at least a $50 \%$ reduction from baseline in the mean number of migraine days per month was assessed as the secondary efficacy outcome. The primary safety outcome was the proportion of participants who suffered adverse events (AEs). The proportions of patients who withdrew from treatment due to AEs and experienced any serious AEs (SAEs) were also assessed. If more than two dosages were used in a single $\mathrm{RCT}$, the outcome values of the most common dosage group were pooled for each type of CGRP mAbs. However, if only one dosage was reported in a single RCT, the outcome values of that dosage were analyzed.

\section{Risk of Bias assessment}

The Cochrane Collaboration's tool was used to assess the risk of bias. Two authors (DH and G-GL) independently judged whether the risk of bias for each criterion was considered low, high or unclear. Disagreements were resolved by discussion.

\section{Statistical analysis}

The heterogeneity between trials was examined using the $\mathrm{I}^{2}$ statistic. For continuous and dichotomous outcome data, the mean difference (MD) and risk ratio (RR) with $95 \%$ confidence intervals (CIs) were respectively 
calculated. In the case of only one available study, we calculated only the MD in migraine frequency or RR for response to treatment. All analyses were carried out using the Review Manager (RevMan 5.3; The Nordic Cochrane Centre, The Cochrane Collaboration, Copenhagen, Denmark). Publication bias was assessed through visual inspection of the funnel plots. Trial sequential analysis (TSA, version 0.9.5.10 Beta, http:// www.ctu. $\mathrm{dk} /$ tsa/downloads.aspx) was managed to evaluate the cumulative evidence according to the information size achieved to date.

\section{Results}

\section{Eligible studies}

Six hundred and nineteen records were identified through database and trial registry searching. After excluding the conference abstracts, reviews, letters and irrelevant studies by screening the titles or abstracts, a total of 33 full texts were retrieved for more detailed inspection. Sixteen of them were repeated publication or post-hoc analysis of the same study and two of them were not RCTs. In addition, 4 articles were excluded for the reasons of chronic migraine [20], healthy subjects $[21,22]$ or without placebo group [23]. Finally, a total of 11 studies met the inclusion and exclusion criteria [14-18, 24-29], and at least 1 outcome could be included in this meta-analysis (Fig. 1).

\section{Characteristics of the included studies}

Eleven studies with data from 4402 unique participants were included. All the included studies were multicenter, randomized, double-blind, placebo-controlled trials involving 5 phase II [25-29] and 6 phase III trials [14-18, 24]. A phase III RCT, namely, PROMISE-1 (NCT02559895), was excluded due to the unpublished original data [30]. Data with the usage of erenumab (70 mg per month), eptinezumab (1000 mg per month), fremanezumab (225 mg per month) and galcanezumab

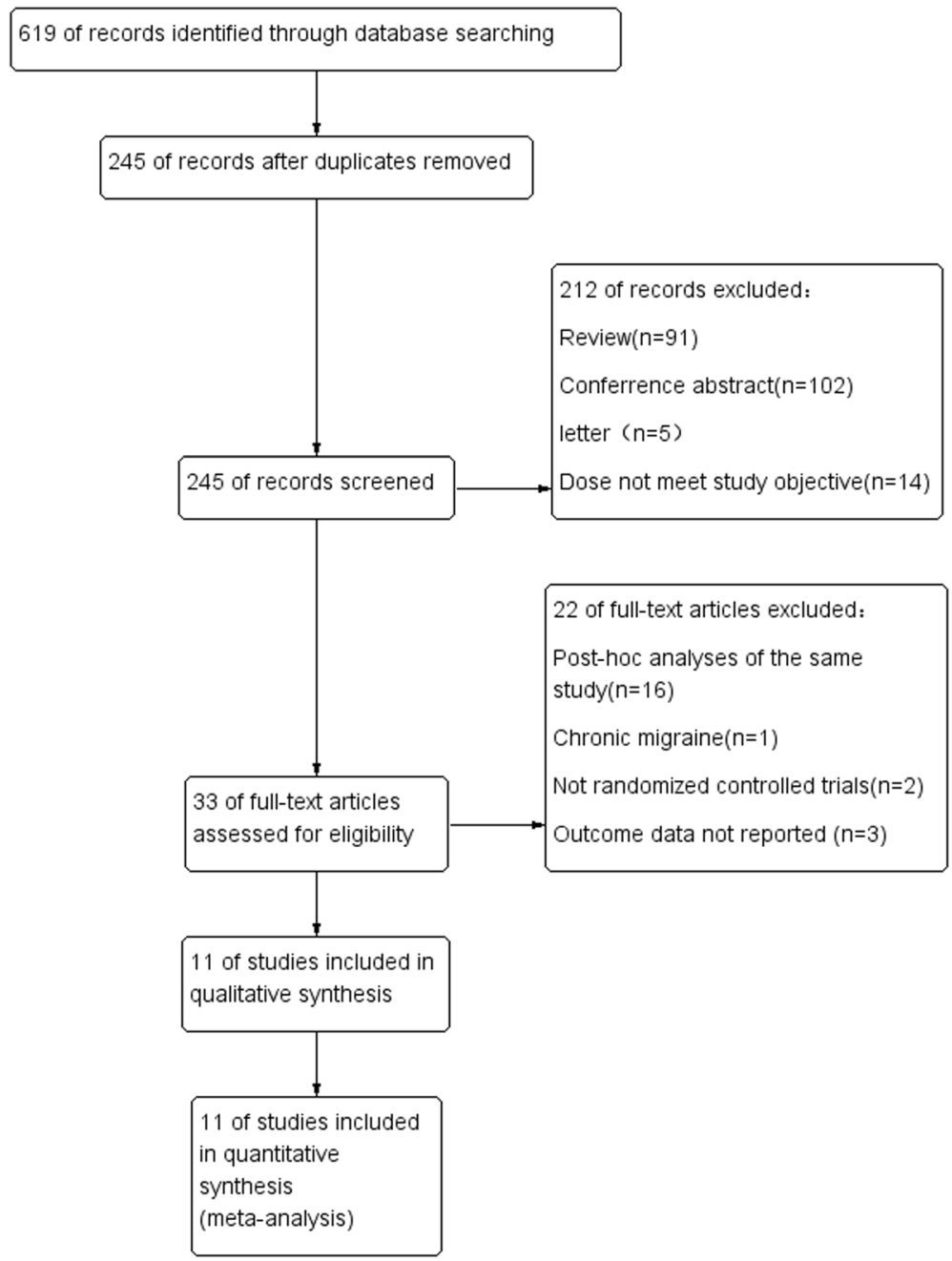

Fig. 1 Flow diagram of study selection process 
(120 mg per month) were selected for pooled analysis. One RCT contained only the dosage group of $140 \mathrm{mg}$ erenumab was included [14]. For galcanezumab, we included a study with the dosage of $150 \mathrm{mg}$ per month, which was relatively close to $120 \mathrm{mg}$ per month [29]. The age of episodic migraine sufferers ranged between 18 and 70 years. Most of the double-blind, placebo controlled trials lasted for 12 weeks, except for three studies with 24 weeks $[17,18,24]$. Detailed characteristics of the included study are shown in Table 1 . According to the Cochrane Handbook of Systematic Review, the risks of bias were assessed (Table 2).

\section{Monthly migraine days}

All the 11 trials reported the changes in monthly migraine days from baseline to endpoint. It was found that erenumab, fremanezumab and galcanezumab exhibited significant differences in this clinical index as compared to placebo group (MD -1.27, 95\% CI -1.61 to -0.92 ; $\mathrm{MD}-1.99,95 \% \mathrm{CI}-3.23$ to 0.75 ; and $\mathrm{MD}-1.57,95 \% \mathrm{CI}-2.03$ to -1.10 , respectively). After pooling, the change in monthly migraine days from baseline to endpoint was significantly greater for CGRP mAbs compared to placebo [weighted mean difference $(\mathrm{WMD})=-1.44,95 \% \mathrm{CI}=$ $\left.(-1.68,-1.19), \mathrm{I}^{2}=6 \%, p<0.00001\right]$. The results are demonstrated in Fig. 2.

\section{Monthly acute migraine-specific medication days}

Eight trials reported the changes in monthly acute migraine-specific medication days from baseline to endpoint. It was found that erenumab, fremanezumab and galcanezumab exhibited significant differences in this clinical index as compared to placebo group (MD -0.96, 95\% CI -1.35 to -0.57 ; MD $-1.39,95 \% \mathrm{CI}-1.94$ to 0.83 ; and $\mathrm{MD}-1.80,95 \% \mathrm{CI}-2.22$ to -1.38 , respectively). After pooling, the change in monthly acute migraine-specific medication days from baseline to endpoint was significantly greater for CGRP mAbs compared to placebo $(\mathrm{WMD}=-1.28,95 \% \mathrm{CI}=[-1.66$, $\left.0.90], \mathrm{I}^{2}=77 \%, p<0.00001\right)$. The results are presented in Fig. 3.

$\geq \mathbf{5 0} \%$ reduction from baseline in monthly migraine days All the 11 trials reported the $50 \%$ responder rate. It was observed that erenumab, fremanezumab and galcanezumab exhibited significant differences in this clinical index as compared to placebo group (RR 1.55, 95\% CI 1.33 to 1.80 ; RR $1.72,95 \%$ CI 1.42 to 2.08 ; and RR 1.51, $95 \%$ CI 1.32 to 1.73 , respectively). After pooling, the change in $\geq 50 \%$ reduction in migraine days per month from baseline to endpoint was remarkably greater for CGRP mAbs compared to placebo $(\mathrm{RR}=1.51,95 \% \mathrm{CI}=$ $\left.[1.37,1.66], \mathrm{I}^{2}=48 \%, p<0.00001\right)$. The results are shown in Fig. 4.

Table 1 Characteristics of the included studies

\begin{tabular}{|c|c|c|c|c|c|c|}
\hline Study (reference no.) & Year & Study design (NCT No.) & Interventions & $\begin{array}{l}\text { Sex (male/female),Age } \\
\text { (mean } \pm \mathrm{SD})\end{array}$ & $\begin{array}{l}\text { Baseline Migraine-days } \\
\text { per month (mean } \pm \mathrm{SD} \text { ) }\end{array}$ & Follow-up \\
\hline Uwe Reuter [14] & 2018 & RCT phase3b, NCT03096834 & $\begin{array}{l}\text { erenumab } 140 \mathrm{mg} \\
\text { Placebo }\end{array}$ & $\begin{array}{l}24 / 97,44.6 \pm 10.5 \\
22 / 103,44.2 \pm 10.6\end{array}$ & $\begin{array}{l}9.2 \pm 2.6 \\
9.3 \pm 2.7\end{array}$ & $12 w$ \\
\hline David W Dodick [15] & 2017 & RCT phase 3, NCT02483585 & $\begin{array}{l}\text { erenumab } 70 \mathrm{mg} \\
\text { Placebo }\end{array}$ & $\begin{array}{l}41 / 245,42 \pm 11 \\
44 / 247,42 \pm 12\end{array}$ & $\begin{array}{l}8.1 \pm 2.7 \\
8.4 \pm 2.6\end{array}$ & $12 w$ \\
\hline Peter J. Goadsby [24] & 2017 & RCT phase 3, NCT02456740 & $\begin{array}{l}\text { erenumab } 70 \mathrm{mg} \\
\text { Placebo }\end{array}$ & $\begin{array}{l}49 / 268,41.1 \pm 11.3 \\
45 / 274,41.3 \pm 11.2\end{array}$ & $\begin{array}{l}8.3 \pm 2.5 \\
8.2 \pm 2.5\end{array}$ & $24 w$ \\
\hline Hong Sun [25] & 2016 & RCT phase 2, NCT01952574 & $\begin{array}{l}\text { erenumab } 70 \mathrm{mg} \\
\text { Placebo }\end{array}$ & $\begin{array}{l}25 / 82,42.6 \pm 9.9 \\
28 / 132,41.4 \pm 10.0\end{array}$ & $\begin{array}{l}8.6 \pm 2.5 \\
8.8 \pm 2.7\end{array}$ & $12 w$ \\
\hline David W Dodick [26] & 2014 & RCT phase 2, NCT01772524 & $\begin{array}{l}\text { Eptinezumab } 1000 \text { mg } \\
\text { Placebo }\end{array}$ & $\begin{array}{l}14 / 67,38.6 \pm 10.8 \\
16 / 66,39.0 \pm 9.6\end{array}$ & $\begin{array}{l}8.4 \pm 2.1 \\
8.8 \pm 2.7\end{array}$ & $12 w$ \\
\hline David W. Dodick [16] & 2018 & RCT phase 3, NCT02629861 & $\begin{array}{l}\text { Fremanezumab } 225 \text { mg } \\
\text { Placebo }\end{array}$ & $\begin{array}{l}46 / 244,42.9 \pm 12.7 \\
47 / 247,41.3 \pm 12.0\end{array}$ & $\begin{array}{l}8.9 \pm 2.6 \\
9.1 \pm 2.7\end{array}$ & $12 w$ \\
\hline Marcelo E Bigal [27] & 2015 & RCT phase 2b, NCT02025556 & $\begin{array}{l}\text { Fremanezumab } 225 \text { mg } \\
\text { Placebo }\end{array}$ & $\begin{array}{l}9 / 87,40.8 \pm 12.4 \\
12 / 92,42.0 \pm 11.6\end{array}$ & $\begin{array}{l}11.5 \pm 1.9 \\
11.5 \pm 2.24\end{array}$ & $12 w$ \\
\hline Vladimir Skljarevski ${ }^{\#}$ [28] & 2018 & RCT phase 2b, NCT02163993 & $\begin{array}{l}\text { Galcanezumab } 120 \mathrm{mg} \\
\text { Placebo }\end{array}$ & $\begin{array}{l}42 / 231,40.6 \pm 11.9 \\
28 / 109,39.5 \pm 12.1\end{array}$ & $\begin{array}{l}6.7 \pm 2.6 \\
6.6 \pm 2.7\end{array}$ & $12 w$ \\
\hline Vladimir Skljarevski [18] & 2017 & RCT Phase 3, NCT02614196 & $\begin{array}{l}\text { galcanezumab } 120 \mathrm{mg} \\
\text { Placebo }\end{array}$ & $\begin{array}{l}34 / 197,40.9 \pm 11.2 \\
68 / 393,42.3 \pm 11.3\end{array}$ & $\begin{array}{l}9.07 \pm 2.9 \\
9.2 \pm 3.0\end{array}$ & $24 w$ \\
\hline Virginia L. Stauffer [17] & 2018 & RCT phase 3, NCT02614183 & $\begin{array}{l}\text { galcanezumab } 120 \mathrm{mg} \\
\text { Placebo }\end{array}$ & $\begin{array}{l}32 / 181,40.9 \pm 11.9 \\
71 / 362,41.3 \pm 11.4\end{array}$ & $\begin{array}{l}9.2 \pm 3.1 \\
9.1 \pm 3.0\end{array}$ & $24 w$ \\
\hline David W Dodick [29] & 2014 & RCT phase 2, NCT01625988 & $\begin{array}{l}\text { galcanezumab } 150 \mathrm{mg} \\
\text { Placebo }\end{array}$ & $\begin{array}{l}19 / 88,40.9 \pm 11.4 \\
14 / 96,41.9 \pm 11.7\end{array}$ & $\begin{array}{l}6.7 \pm 2.4 \\
7.0 \pm 2.5\end{array}$ & $12 w$ \\
\hline
\end{tabular}


Table 2 Assessment on the methodological strategies of the included studies

\begin{tabular}{|c|c|c|c|c|c|c|}
\hline Trial ID & $\begin{array}{l}\text { Random sequence } \\
\text { generation }\end{array}$ & $\begin{array}{l}\text { Allocation } \\
\text { concealment }\end{array}$ & Blinding & $\begin{array}{l}\text { Incomplete } \\
\text { outcome data }\end{array}$ & $\begin{array}{l}\text { Selective outcome } \\
\text { reporting }\end{array}$ & $\begin{array}{l}\text { Other sources } \\
\text { of bias }\end{array}$ \\
\hline Uwe Reuter 2018 & Low risk & Low risk & Low risk & Low risk & Low risk & Unclear risk \\
\hline David W Dodick 2017 & Low risk & Low risk & Low risk & Low risk & Low risk & Unclear risk \\
\hline Peter J. Goadsby 2017 & Low risk & Low risk & Low risk & Low risk & Low risk & Unclear risk \\
\hline Hong Sun 2016 & Low risk & Low risk & Low risk & Low risk & Low risk & Unclear risk \\
\hline David W Dodick 2014 & Low risk & Low risk & Low risk & Low risk & Low risk & Unclear risk \\
\hline David W. Dodick 2018 & Low risk & Low risk & Low risk & Low risk & Low risk & Unclear risk \\
\hline Marcelo E Bigal 2015 & Low risk & Low risk & Low risk & Low risk & Low risk & Unclear risk \\
\hline Vladimir Skljarevski 2018 & Low risk & Low risk & Low risk & Low risk & Low risk & Unclear risk \\
\hline Vladimir Skljarevski 2017 & Low risk & Low risk & Low risk & Low risk & Low risk & Unclear risk \\
\hline Virginia L. Stauffer 2018 & Low risk & Low risk & Low risk & Low risk & Low risk & Unclear risk \\
\hline David W Dodick 2014 & Low risk & Low risk & Low risk & Low risk & Low risk & Unclear risk \\
\hline
\end{tabular}

\section{Adverse events}

For the safety of CGRP mAb, the incidence of all types of AE was reported in the 11 studies. Regardless of pooled or subgroup analysis, the results demonstrated no significant difference between each CGRP mAb and placebo groups (Fig. 5).
Apart from AEs, we also assessed the treatment withdrawal rates due to AEs, incidence of SAEs and reported specific AEs. Of all the safety outcome measures, only the level of injection-site pain was significantly different between CGRP mAb and placebo groups (Table 3).

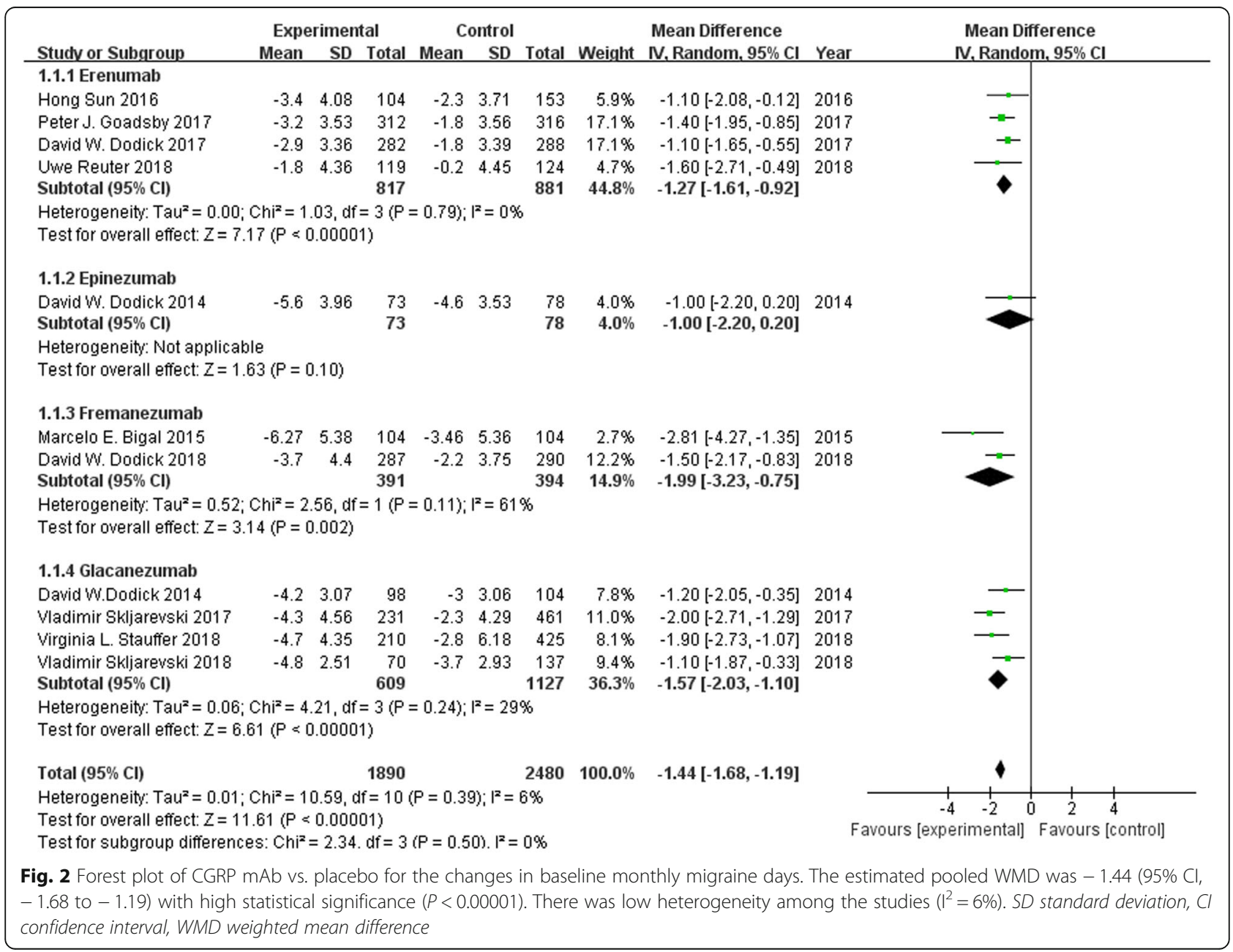




\begin{tabular}{|c|c|c|c|c|c|c|c|c|c|c|}
\hline \multirow[b]{2}{*}{ Study or Subgroup } & \multicolumn{3}{|c|}{ Experimental } & \multicolumn{3}{|c|}{ Control } & \multirow[b]{2}{*}{ Weight } & \multirow{2}{*}{$\begin{array}{l}\text { Mean Difference } \\
\text { IV, Random, } 95 \% \mathrm{Cl}\end{array}$} & \multirow{2}{*}{\multicolumn{2}{|c|}{$\begin{array}{l}\text { Mean Difference } \\
\text { IV, Random, } 95 \% \mathrm{Cl}\end{array}$}} \\
\hline & Mean & SD & Total & Mean & SD & Total & & & & \\
\hline \multicolumn{11}{|c|}{ 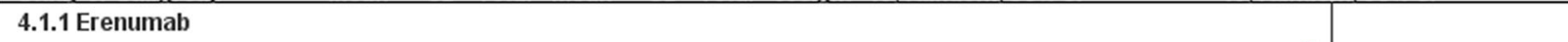 } \\
\hline David W. Dodick 2017 & -1.2 & 1.68 & 282 & -0.6 & 1.7 & 288 & $16.8 \%$ & $-0.60[-0.88,-0.32]$ & 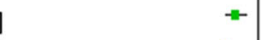 & \\
\hline Hong Sun 2016 & -1.6 & 3.06 & 104 & -0.7 & 2.47 & 153 & $11.3 \%$ & $-0.90[-1.61,-0.19]$ & - & \\
\hline Peter J. Goadsby 2017 & -1.1 & 1.77 & 312 & -0.2 & 1.78 & 316 & $16.8 \%$ & $-0.90[-1.18,-0.62]$ & - & \\
\hline Uwe Reuter 2018 & -1.3 & 2.18 & 119 & 0.5 & 3.34 & 124 & $11.3 \%$ & $-1.80[-2.51,-1.09]$ & & \\
\hline Subtotal $(95 \% \mathrm{Cl})$ & & & 817 & & & 881 & $56.2 \%$ & $-0.96[-1.35,-0.57]$ & & \\
\hline \multicolumn{11}{|c|}{$\begin{array}{l}\text { Heterogeneity: } \text { Tau }^{2}=0.10 ; \mathrm{Chi}^{2}=10.16, \mathrm{df}=3(\mathrm{P}=0.02) ; \mathrm{I}^{2}=70 \% \\
\text { Test for overall effect: } Z=4.80(\mathrm{P}<0.00001)\end{array}$} \\
\hline \multicolumn{11}{|l|}{ 4.1.3 Fremanezumab } \\
\hline David W. Dodick 2018 & -3 & 3.56 & 287 & -1.7 & 4 & 290 & $12.4 \%$ & $-1.30[-1.92,-0.68]$ & - & \\
\hline Marcelo E. Bigal 2015 & -4.86 & 4.64 & 95 & -3.1 & 4.64 & 104 & $5.9 \%$ & $-1.76[-3.05,-0.47]$ & & \\
\hline Subtotal $(95 \% \mathrm{Cl})$ & & & 382 & & & 394 & $18.3 \%$ & $-1.39[-1.94,-0.83]$ & & \\
\hline \multicolumn{11}{|c|}{ Heterogeneity: $\mathrm{Tau}^{2}=0.00 ; \mathrm{Chi}^{2}=0.40, \mathrm{df}=1(\mathrm{P}=0.53) ; \mathrm{F}^{2}=0 \%$} \\
\hline \multicolumn{11}{|c|}{ Test for overall effect: $Z=4.87(P<0.00001)$} \\
\hline \multicolumn{11}{|l|}{ 4.1.4 Galcanezumab } \\
\hline Virginia L. Stauffer 2018 & -4 & 3.63 & 210 & -2.2 & 4.12 & 425 & $12.3 \%$ & $-1.80[-2.43,-1.17]$ & $\rightarrow$ & \\
\hline Vladimir Skljarevski 2017 & -3.7 & 3.04 & 231 & -1.9 & 4.29 & 461 & $13.3 \%$ & $-1.80[-2.35,-1.25]$ & & \\
\hline Subtotal (95\% Cl) & & & 441 & & & 886 & $25.5 \%$ & $-1.80[-2.22,-1.38]$ & & \\
\hline \multicolumn{11}{|c|}{$\begin{array}{l}\text { Heterogeneity: } \text { Tau }^{2}=0.00 ; \mathrm{Chi}^{2}=0.00, \mathrm{df}=1(\mathrm{P}=1.00) ; \mathrm{I}^{2}=0 \% \\
\text { Test for overall effect: } Z=8.49(\mathrm{P}<0.00001)\end{array}$} \\
\hline \multirow{2}{*}{\multicolumn{7}{|c|}{$\begin{array}{l}\text { Total }(95 \% \mathrm{Cl}) \quad 1640 \quad 2161 \\
\text { Heterogeneity: } \text { Tau }^{2}=0.20 ; \mathrm{Chi}^{2}=29.90, \mathrm{df}=7(\mathrm{P}<0.0001) ;\left.\right|^{2}=77 \% \\
\text { Test for overall effect: } \mathrm{Z}=6.62(\mathrm{P}<0.00001) \\
\text { Test for subgroup differences: } \mathrm{Chi}^{2}=8.42 . \mathrm{df}=2(\mathrm{P}=0.01) . \mathrm{I}^{2}=76.2 \%\end{array}$}} & $100.0 \%$ & $-1.28[-1.66,-0.90]$ & \multirow{2}{*}{\multicolumn{2}{|c|}{\begin{tabular}{cc|ccc}
-4 & 1 & & 1 & 1 \\
Favours [experimental] & Favours [control]
\end{tabular}}} \\
\hline & & & & & & & & & & \\
\hline \multicolumn{11}{|c|}{$\begin{array}{l}\text { Fig. } 3 \text { Forest plot of CGRP mAb vs. placebo for the changes in baseline monthly acute migraine-specifc medication days. The estimated pooled } \\
\text { WMD was }-1.28(95 \% \mathrm{Cl},-1.66 \text { to }-0.90) \text { with high statistical significance }(P<0.00001) \text {. There was high heterogeneity among the studies }\left(I^{2}=\right. \\
77 \%) \text {. SD standard deviation, } C l \text { confidence interval, WMD weighted mean difference }\end{array}$} \\
\hline
\end{tabular}

\section{Trial sequential analysis}

TSA was performed to evaluate random errors caused by limited data and repetitive testing of accumulating data. For the TSA, the required information size was calculated based on low risk of bias model. The type I error $(\alpha)$ was set at 0.05 and the power $(1-\beta)$ at 0.80 .The cumulative z-curve crossed both the traditional boundary and the trial sequential monitoring boundary, suggesting firm evidence for changes in monthly migraine days from baseline to endpoint (Fig. 6). Similarly, TSA supported sufficient evidence for changes in monthly acute migraine-specific medication days and $\geq 50 \%$ reduction in migraine days per month from baseline to endpoint (Additional file 1: Figure S1, S2).

\section{Publication bias}

A funnel plot of all studies (Fig. 7) explored the potential for publication bias in our sample. No obvious asymmetry was identified in the funnel plot, indicating that there was no publication bias.

\section{Discussion}

In this meta-analysis of 11 high-quality studies involving a total of 4402 episodic migraineurs, we found that CGRP mAbs could reduce the numbers of monthly migraine days and acute migraine-specific medication days, as well as improve the $50 \%$ responder rate, as compared to placebo group. TSA was used to adjust random errors and calculate the sample size needed, and it was found that the evidence in our meta-analysis was reliable and conclusive. In addition, CGRP-binding mAbs were well tolerated among episodic migraineurs, as the incidence of AEs and treatment withdrawal rates were relatively similar between CGRP mAbs and placebo groups. Moreover, only injection-site pain was significantly different between CGRP mAbs and placebo groups. We speculated that it could be related to the subcutaneous delivery route of CGRP mAb administration. The outcomes of subgroup analysis revealed that erenumab, fremanezumab and galcanezumab exhibited similar efficacy and safety in patients with episodic migraine. Stephen D. Silberstein et al. [8] did a subgroup analysis of two phase 3 studies which we have included in our meta-analysis $[17,18]$ to evaluate the efficacy of galcanezumab for HFEM (8-14 monthly MHDs) and LFEM (4-7 monthly MHDs). And it was found that galcanezumab was as effective in patients with HFEM as in those with LFEM. Associated symptoms, quality of life, and disability were similarly improved in patients with HFEM or LFEM. While, the reported clinical information on eptinezumab are limited, resulting in only one study included for this mAb. A large multicenter RCT of eptinezumab, also known as PROMISE1 (NCT02559895), has been completed recently. Still, 


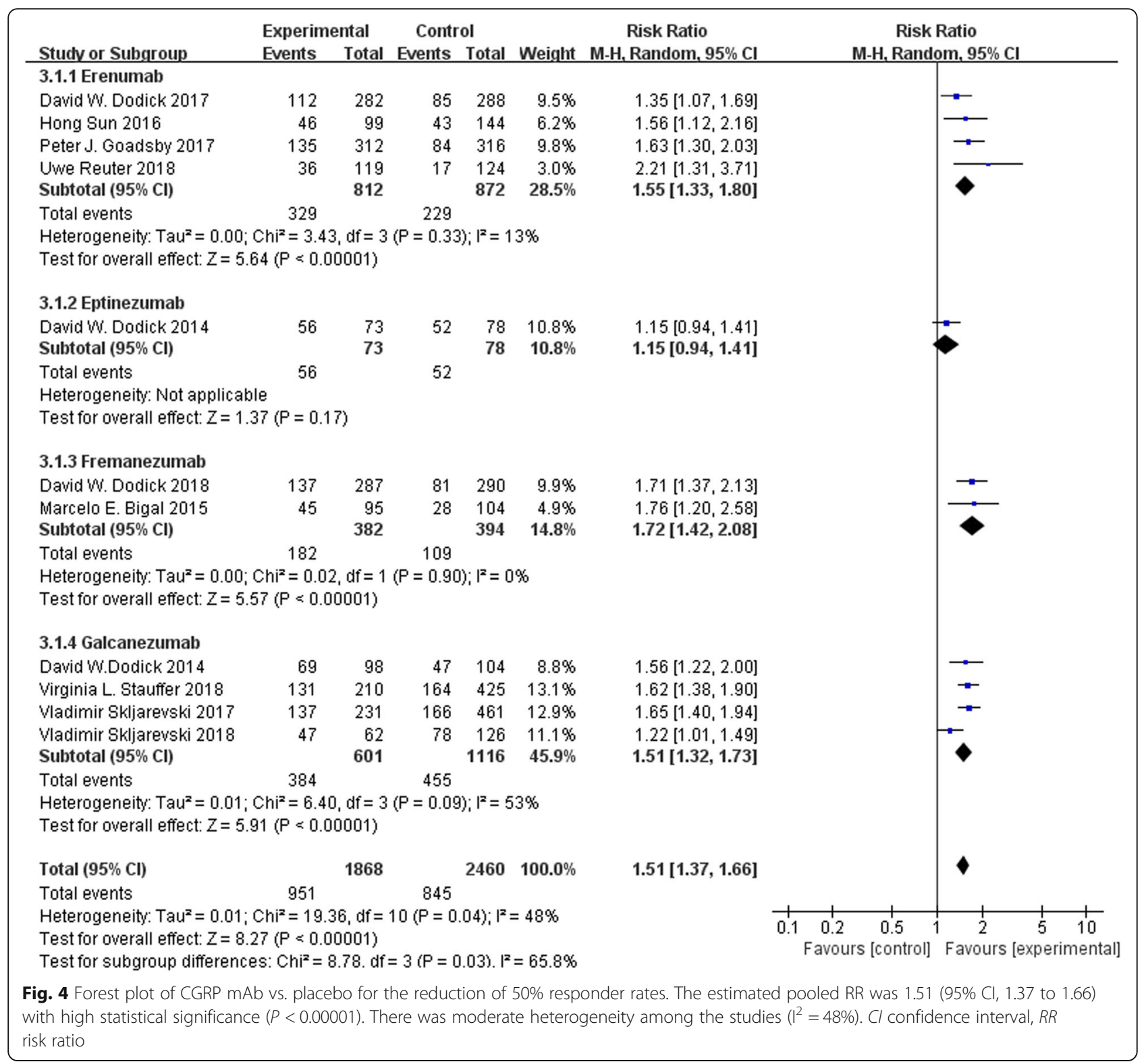

more research is needed to confirm the treatment effects of eptinezumab on episodic migraine.

Compared to previous attempts [13, 31-33] aimed to summarize the evidence on CGRP mAb treatment in episodic migraine, this study provides a systematic, qualified, updated and more detailed assessment of the efficacy and safety of various CGRP mAbs. Indeed, this meta-analysis covered a greater number of studies and larger sample size, in order to obtain more precise estimates of the treatment effects. To the best of our knowledge, this is the first comprehensive study that includes 6 phase III trials to evaluate the efficacy and safety of CGRP-binding mAbs in patients with episodic migraine. The previous meta-analysis [13] published in 2018 is consisted of repeated trials and chronic migraine cases, leading to a doubtful conclusion. Another meta-analysis [33] recently published in 2019 contained a mixture of episodic and chronic migraineurs. Although the most recent meta-analysis has relatively similar included RCTs compared with our study, it mainly focused on the safety and tolerability rather than the efficacy of CGRP mAb in patients with episodic migraine [32].

In recent years, the new targets for migraine treatment are moving toward the trigeminal sensory neuropeptide CGRP or its receptor [34]. It's reported that most of CGRP is released from trigeminal afferents both in meningeal tissues and at the first synapse in the spinal trigeminal nucleus [35]. And CGRP receptors are distributed in the central and peripheral nervous system, as well as in the cardiovascular system [36]. Since CGRP 


\begin{tabular}{|c|c|c|c|c|c|c|c|}
\hline \multirow[b]{2}{*}{ Study or Subgroup } & \multicolumn{2}{|c|}{ Experimental } & \multicolumn{2}{|c|}{ Control } & \multirow{2}{*}{ Weight } & \multirow{2}{*}{$\begin{array}{c}\text { Risk Ratio } \\
\text { M-H, Random, } 95 \% \mathrm{Cl} \\
\end{array}$} & \multirow{2}{*}{$\begin{array}{c}\text { Risk Ratio } \\
\text { M-H, Random, } 95 \% \mathrm{Cl}\end{array}$} \\
\hline & Events & Total & Events & Total & & & \\
\hline \multicolumn{8}{|l|}{ 2.1.1 Erenumab } \\
\hline David W. Dodick 2018 & 136 & 283 & 158 & 289 & $10.1 \%$ & $0.88[0.75,1.03]$ & ] \\
\hline Hong Sun 2016 & 57 & 106 & 82 & 153 & $5.7 \%$ & $1.00[0.80,1.26]$ & \\
\hline Peter J. Goadsby 2017 & 180 & 314 & 201 & 319 & $14.0 \%$ & $0.91[0.80,1.03]$ & \\
\hline Uwe Reuter 2018 & 65 & 119 & 67 & 124 & $5.6 \%$ & $1.01[0.80,1.27]$ & \\
\hline Subtotal $(95 \% \mathrm{Cl})$ & & 822 & & 885 & $35.5 \%$ & $0.93[0.85,1.01]$ & \\
\hline Total events & 438 & & 508 & & & & \\
\hline \multicolumn{8}{|c|}{ Heterogeneity: $\operatorname{Tau}^{2}=0.00 ; \mathrm{Chi}^{2}=1.50, \mathrm{df}=3(\mathrm{P}=0.68) ; \mathrm{I}^{2}=0 \%$} \\
\hline \multicolumn{8}{|c|}{ Test for overall effect: $Z=1.77(P=0.08)$} \\
\hline \multicolumn{8}{|l|}{ 2.1.2 Eptinezumab } \\
\hline David W. Dodick 2014 & 46 & 81 & 43 & 82 & $4.0 \%$ & $1.08[0.82,1.43]$ & \\
\hline Subtotal $(95 \% \mathrm{Cl})$ & & 81 & & 82 & $4.0 \%$ & $1.08[0.82,1.43]$ & \\
\hline Total events & 46 & & 43 & & & & \\
\hline \multicolumn{8}{|c|}{ Heterogeneity: Not applicable } \\
\hline \multicolumn{8}{|c|}{ Test for overall effect: $Z=0.56(P=0.58)$} \\
\hline \multicolumn{8}{|l|}{ 2.1.3 Fremanezumab } \\
\hline David W. Dodick 2018 & 192 & 290 & 171 & 293 & $14.1 \%$ & $1.13[1.00,1.29]$ & $\rightarrow$ \\
\hline Marcelo E. Bigal 2015 & 44 & 96 & 58 & 104 & $4.1 \%$ & $0.82[0.62,1.08]$ & \\
\hline Subtotal $(95 \% \mathrm{Cl})$ & & 386 & & 397 & $18.2 \%$ & $0.99[0.72,1.35]$ & \\
\hline Total events & 236 & & 229 & & & & \\
\hline \multirow{2}{*}{\multicolumn{8}{|c|}{$\begin{array}{l}\text { Heterogeneity: } \text { Tau }^{2}=0.04 ; \mathrm{Chi}^{2}=4.36, \mathrm{df}=1(\mathrm{P}=0.04) ; \mathrm{I}^{2}=77 \% \\
\text { Test for overall effect: } Z=0.07(P=0.95)\end{array}$}} \\
\hline & & & & & & & \\
\hline \multicolumn{8}{|l|}{ 2.1.4 Galcanezumab } \\
\hline David W.Dodick 2014 & 77 & 107 & 74 & 110 & $8.8 \%$ & $1.07[0.90,1.28]$ & - \\
\hline Virginia L. Stauffer 2018 & 135 & 206 & 261 & 432 & $14.3 \%$ & $1.08[0.96,1.23]$ & $=$ \\
\hline Vladimir Skljarevski 2017 & 147 & 226 & 287 & 461 & $15.2 \%$ & $1.04[0.93,1.18]$ & - \\
\hline Vladimir Skljarevski 2018 & 36 & 70 & 70 & 137 & $4.0 \%$ & $1.01[0.76,1.33]$ & \\
\hline Subtotal $(95 \% \mathrm{Cl})$ & & 609 & & 1140 & $42.4 \%$ & $1.06[0.98,1.14]$ & 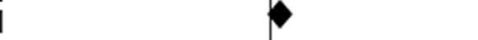 \\
\hline Total events & 395 & & 692 & & & & \\
\hline \multirow{2}{*}{\multicolumn{8}{|c|}{$\begin{array}{l}\text { Heterogeneity: } \mathrm{Tau}^{2}=0.00 ; \mathrm{Chi}^{2}=0.33, \mathrm{df}=3(\mathrm{P}=0.95) ; \mathrm{I}^{2}=0 \% \\
\text { Test for owerall effect: } \mathrm{Z}=1.54(\mathrm{P}=0.12)\end{array}$}} \\
\hline & & & & & & & \\
\hline Total $(95 \% \mathrm{Cl})$ & & 1898 & & 2504 & $100.0 \%$ & $1.01[0.95,1.07]$ & \\
\hline Total events & 1115 & & 1472 & & & & \\
\hline Heterogeneity: $\operatorname{Tau}^{2}=0.00$ & $\mathrm{Chi}^{2}=13$ & $0, d f=1$ & $10(P=0$. & $22) ; 1^{2}=$ & $=24 \%$ & & 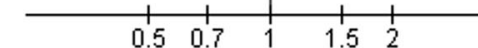 \\
\hline Test for overall effect: $Z=$ & $39(P=0.6$ & & & & & & 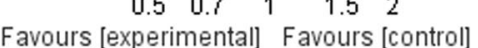 \\
\hline Test for subgroup differen & es: $\mathrm{Chi}^{2}=$ & $80 . \mathrm{df}=$ & $=3(P=0$ & 12). $I^{2}$ & $=48.3 \%$ & & \\
\hline $\begin{array}{l}\text { Fig. } 5 \text { Forest plot of CGRP m } \\
\text { statistical significance }(P>0 . C\end{array}$ & $\begin{array}{l}\text { b vs. plac } \\
\text { ). There } n\end{array}$ & $\begin{array}{l}\text { bo for } \\
\text { s low h }\end{array}$ & | types o & $f$ adve & rse events. & 5. The estimated pooled $R$ & $\begin{array}{l}\text { RR was } 1.01(95 \% \mathrm{Cl}, 0.95 \text { to } 1.07) \text { without } \\
\text { nfidence interval, RR risk ratio }\end{array}$ \\
\hline
\end{tabular}

Table 3 Summary of adverse events among the included RCTs

\begin{tabular}{|c|c|c|c|c|c|}
\hline & CGRP mAb(n/N) & Placebo(n/N) & $1^{2}$ & odds ratio $[95 \% \mathrm{Cl}]$ & $p$ value \\
\hline Withdrawal due to AEs & $38 / 1898$ & $35 / 2504$ & $0 \%$ & $1.46[0.90,2.37]$ & 0.12 \\
\hline \multicolumn{6}{|l|}{ Specific AEs } \\
\hline any serious events & $1115 / 1898$ & $1472 / 2504$ & $25 \%$ & $1.02[0.90,1.15]$ & 0.79 \\
\hline dizziness & $29 / 835$ & $31 / 1313$ & $0 \%$ & $1.47[0.87,2.49]$ & 0.15 \\
\hline fatigue & $36 / 1515$ & $39 / 1825$ & $0 \%$ & $1.15[0.72,1.83]$ & 0.55 \\
\hline influenza & $26 / 1231$ & $41 / 1758$ & $5 \%$ & $0.87[0.53,1.45]$ & 0.6 \\
\hline injection site pain & $167 / 1501$ & $148 / 1837$ & $35 \%$ & $1.44[1.13,1.84]$ & 0.004 \\
\hline migraine & $12 / 1086$ & $17 / 1379$ & $11 \%$ & $0.83[0.41,1.71]$ & 0.62 \\
\hline nasopharyngitis & $115 / 1817$ & $163 / 2422$ & $1 \%$ & $0.96[0.75,1.24]$ & 0.78 \\
\hline nausea & $34 / 1553$ & $61 / 1919$ & $0 \%$ & $0.68[0.45,1.05]$ & 0.08 \\
\hline upper respiratory tract infection & $117 / 1692$ & $123 / 2072$ & $0 \%$ & $1.25[0.96,1.63]$ & 0.1 \\
\hline urinary tract infection & $22 / 1270$ & $33 / 1519$ & $0 \%$ & $0.91[0.53,1.56]$ & 0.73 \\
\hline
\end{tabular}



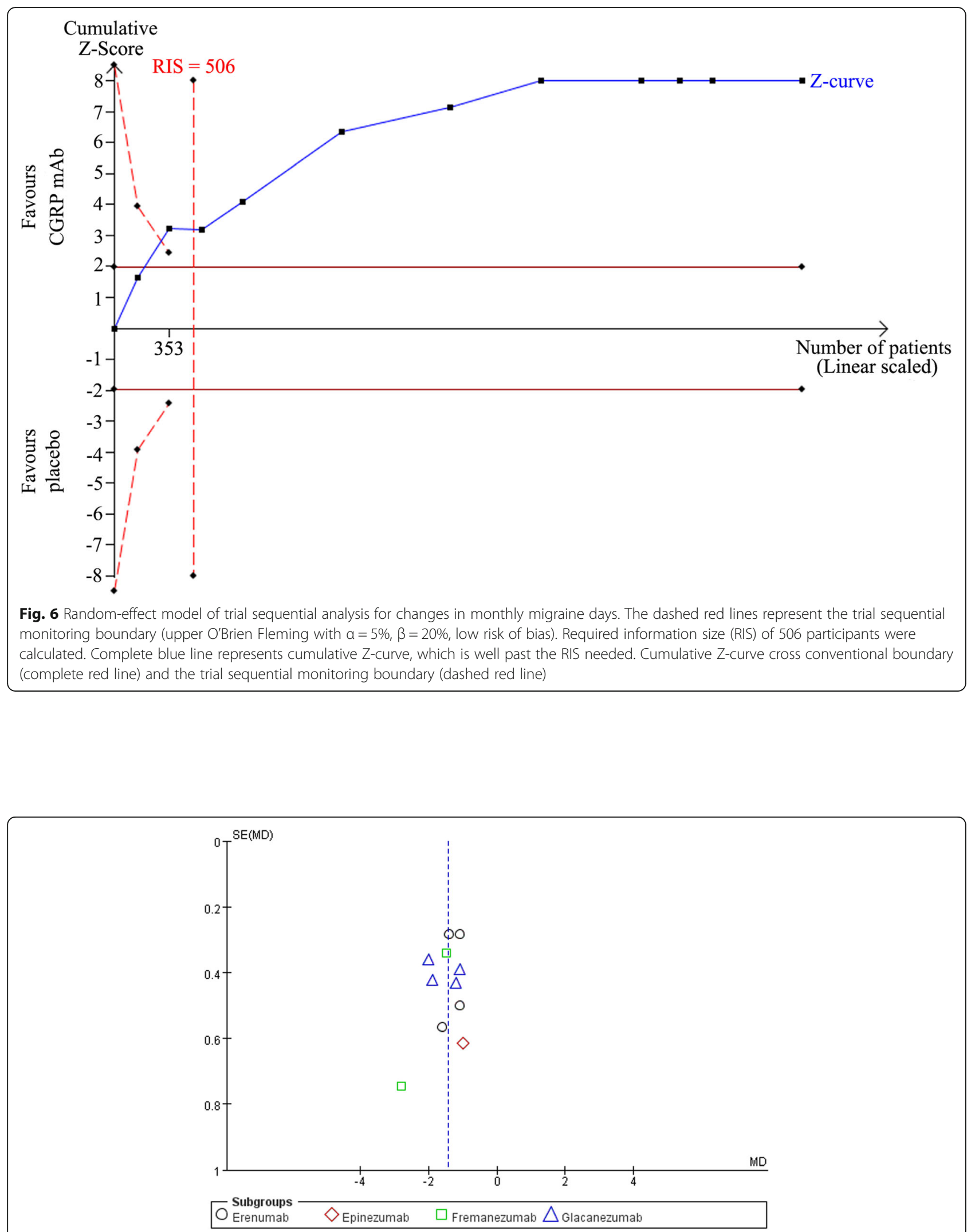

Fig. 7 Funnel plot of effect size by standard error (surrogate for study size) across all studies. No obvious asymmetry was identified in the funnel plot, indicating that there was no publication bias. SE standard error, MD mean difference 
YYF, GYG and WLG participated in data collection and statistical analysis. All authors reviewed and approved the final version of the manuscript.

\section{Funding}

This work was supported by the National Natural Science Foundation of China under Grant No. 81873750 and the Wuhan science and technology plan project under Grant No. 2018060401011316. The funding bodies played no role in the design of the study and collection, analysis, and interpretation of data and in writing the manuscript.

\section{Availability of data and materials}

The data is available on request to the corresponding author.

\section{Ethics approval and consent to participate}

Not applicable.

\section{Consent for publication}

Not applicable.

\section{Competing interests}

The authors declare that they have no competing interests.

\section{Received: 28 August 2019 Accepted: 4 February 2020}

\section{Published online: 15 February 2020}

\section{References}

1. Russo AF. Calcitonin gene-related peptide (CGRP): a new target for migraine. Annu Rev Pharmacol Toxicol. 2015;55:533-52.

2. Russo A, Coppola G, Pierelli F, Parisi V, Silvestro M, Tessitore A, et al. Pain perception and migraine. Front Neurol. 2018;9:576.

3. Forouzanfar MH, Alexander L, Anderson HR, Bachman VF, Biryukov S, Brauer $\mathrm{M}$, et al. Global, regional, and national comparative risk assessment of 79 behavioural, environmental and occupational, and metabolic risks or clusters of risks in 188 countries, 1990-2013: a systematic analysis for the global burden of disease study 2013. Lancet. 2015;386:2287-323.

4. Steiner TJ, Birbeck GL, Jensen RH, Katsarava Z, Stovner $\sqcup$, Martelletti P. Headache disorders are third cause of disability worldwide. J Headache Pain. 2015:16:58.

5. Steiner TJ, Stovner LJ, Birbeck GL. Migraine: the seventh disabler. Cephalalgia. 2013;33:289-90.

6. Tinsley A, Rothrock JF. What are we missing in the diagnostic criteria for migraine? Curr Pain Headache Rep. 2018;22:1-5.

7. Bigal ME, Lipton RB. Clinical course in migraine: conceptualizing migraine transformation. Neurology. 2008;71:848-55.

8. Silberstein SD, Stauffer VL, Day KA, Lipsius S, Wilson M. Galcanezumab in episodic migraine: subgroup analyses of efficacy by high versus low frequency of migraine headaches in phase 3 studies (EVOLVE-1 \& EVOLVE-2). J Headache Pain. 2019:20:75

9. Charles A. Migraine. N Engl J Med. 2017:377:553-61.

10. Huang T, Lai T. Taiwan headache society TGSO. Medical Treatment Guidelines for Preventive Treatment of Migraine. Acta Neurologica Taiwanica. 2017:26:33

11. Hsu YC, Lin KC, Taiwan HST. Medical treatment guidelines for acute migraine attacks. Acta Neurol Taiwanica. 2017;26:78-96.

12. Edvinsson L. The Trigeminovascular pathway: role of CGRP and CGRP receptors in migraine. Headache. 2017:57(Suppl 2):47-55.

13. Zhu Y, Liu Y, Zhao J, Han Q, Liu L, Shen X. The efficacy and safety of calcitonin gene-related peptide monoclonal antibody for episodic migraine: a meta-analysis. Neurol Sci. 2018:39:2097-106.

14. Reuter U, Goadsby PJ, Lanteri-Minet M, Wen S, Hours-Zesiger P, Ferrari MD, et al. Efficacy and tolerability of erenumab in patients with episodic migraine in whom two-to-four previous preventive treatments were unsuccessful: a randomised, double-blind, placebo-controlled, phase $3 b$ study. Lancet. 2018;392:2280-7

15. Dodick DW, Ashina M, Brandes JL, Kudrow D, Lanteri-Minet M, Osipova V, et al. ARISE: a phase 3 randomized trial of erenumab for episodic migraine. Cephalalgia. 2017:38:1026-37.

16. Dodick DW, Silberstein SD, Bigal ME, Yeung PP, Goadsby PJ, Blankenbiller T, et al. Effect of Fremanezumab compared with placebo for prevention of episodic migraine: a randomized clinical trial. JAMA. 2018;319:1999-2008.
17. Stauffer VL, Dodick DW, Zhang Q, Carter JN, Ailani J, Conley RR. Evaluation of Galcanezumab for the prevention of episodic migraine: the EVOLVE-1 randomized clinical trial. JAMA Neurol. 2018;75:1080-8.

18. Skljarevski V, Matharu M, Millen BA, Ossipov MH, Kim B, Yang JY. Efficacy and safety of galcanezumab for the prevention of episodic migraine: results of the EVOLVE-2 phase 3 randomized controlled clinical trial. Cephalalgia. 2017:38:1442-54.

19. Headache Classification Committee of the International Headache Society (IHS). The International Classification of Headache Disorders, 3rd edition (beta version). Cephalalgia. 2013;33:629-808.

20. Bigal ME, Edvinsson L, Rapoport AM, Lipton RB, Spierings EL, Diener HC et al. Safety, tolerability, and efficacy of TEV-48125 for preventive treatment of chronic migraine: a multicentre, randomised, double-blind, placebocontrolled, phase 2b study. Lancet Neurol. 2015;14:1091-100.

21. de Hoon J, Van Hecken A, Vandermeulen C, Yan L, Smith B, Chen JS, et al. Phase I, randomized, double-blind, placebo-controlled, single-dose, and multiple-dose studies of Erenumab in healthy subjects and patients with migraine. Clin Pharmacol Ther. 2018;103:815-25.

22. Cohen-Barak O, Weiss S, Rasamoelisolo M, Faulhaber N, Yeung PP, Loupe PS, et al. A phase 1 study to assess the pharmacokinetics, safety, and tolerability of fremanezumab doses (225 mg, $675 \mathrm{mg}$ and $900 \mathrm{mg}$ ) in Japanese and Caucasian healthy subjects. Cephalalgia. 2018;38:1960-71.

23. Camporeale A, Kudrow D, Sides R, Wang S, Van Dycke A, Selzler KJ, et al. A phase 3, long-term, open-label safety study of Galcanezumab in patients with migraine. BMC Neurol. 2018;18:188.

24. Goadsby PJ, Reuter U, Hallstrom Y, Broessner G, Bonner JH, Zhang F, et al. A controlled trial of Erenumab for episodic migraine. N Engl J Med. 2017;377: 2123-32

25. Sun H, Dodick DW, Silberstein S, Goadsby PJ, Reuter U, Ashina M, et al. Safety and efficacy of AMG 334 for prevention of episodic migraine: a randomised, double-blind, placebo-controlled, phase 2 trial. Lancet Neurol. 2016;15:382-90.

26. Dodick DW, Goadsby PJ, Silberstein SD, Lipton RB, Olesen J, Ashina M, et al. Safety and efficacy of ALD403, an antibody to calcitonin gene-related peptide, for the prevention of frequent episodic migraine: a randomised, double-blind, placebo-controlled, exploratory phase 2 trial. Lancet Neurol. 2014;13:1100-7.

27. Bigal ME, Dodick DW, Rapoport AM, Silberstein SD, Ma Y, Yang R, et al. Safety, tolerability, and efficacy of TEV-48125 for preventive treatment of high-frequency episodic migraine: a multicentre, randomised, double-blind, placebo-controlled, phase 2b study. Lancet Neurol. 2015;14:1081-90.

28. Skljarevski V, Oakes TM, Zhang Q, Ferguson MB, Martinez J, Camporeale A, et al. Effect of different doses of Galcanezumab vs placebo for episodic migraine prevention: a randomized clinical trial. JAMA Neurol. 2018;75:187-93.

29. Dodick DW, Goadsby PJ, Spierings EL, Scherer JC, Sweeney SP, Grayzel DS. Safety and efficacy of LY2951742, a monoclonal antibody to calcitonin gene-related peptide, for the prevention of migraine: a phase 2 , randomised, double-blind, placebo-controlled study. Lancet Neurol. 2014;13: 885-92.

30. Silberstein SD, Kudrow D, Saper J, Janelidze M, Smith T, Dodick DW, et al. Eptinezumab results for the prevention of episodic migraine over one year in the PROMISE-1 (PRevention of migraine via intravenous Eptinezumab safety and efficacy-1) trial. Headache. 2018:58:1298.

31. Hong P, Wu X, Liu Y. Calcitonin gene-related peptide monoclonal antibody for preventive treatment of episodic migraine: a meta analysis. Clin Neurol Neurosurg. 2017;154:74-8

32. Xu D, Chen D, Zhu L, Tan G, Wang H, Zhang Y, et al. Safety and tolerability of calcitonin-gene-related peptide binding monoclonal antibodies for the prevention of episodic migraine - a meta-analysis of randomized controlled trials. Cephalalgia. 2019:39:1164-79.

33. Lattanzi S, Brigo F, Trinka E, Vernieri F, Corradetti T, Dobran M, et al. Erenumab for preventive treatment of migraine: a systematic review and Meta-analysis of efficacy and safety. Drugs. 2019;79(4):417-31

34. Edvinsson L, Haanes KA, Warfvinge $K$, Krause DN. CGRP as the target of new migraine therapies - successful translation from bench to clinic. Nat Rev Neurol. 2018:14:338-50.

35. Messlinger K. The big CGRP flood - sources, sinks and signalling sites in the trigeminovascular system. J Headache Pain. 2018;19:22.

36. Favoni V, Giani L, Al-Hassany L, Asioli GM, Butera C, de Boer I, et al. CGRP and migraine from a cardiovascular point of view: what do we expect from blocking CGRP? J Headache Pain. 2019;20:27. 
37. Manoukian R, Sun H, Miller S, Shi D, Chan B, Xu C. Effects of monoclonal antagonist antibodies on calcitonin gene-related peptide receptor function and trafficking. J Headache Pain. 2019;20:44.

38. Gonzalez-Hernandez A, Marichal-Cancino BA, MaassenVanDenBrink A, Villalon CM. Side effects associated with current and prospective antimigraine pharmacotherapies. Expert Opin Drug Metab Toxicol. 2018;14: 25-41.

39. Bell IM. Calcitonin gene-related peptide receptor antagonists: new therapeutic agents for migraine. J Med Chem. 2014;57:7838-58.

40. Raffaelli B, Mussetto V, Israel H, Neeb L, Reuter U. Erenumab and galcanezumab in chronic migraine prevention: effects after treatment termination. J Headache Pain. 2019;20:66.

\section{Publisher's Note}

Springer Nature remains neutral with regard to jurisdictional claims in published maps and institutional affiliations.

- fast, convenient online submission

- thorough peer review by experienced researchers in your field

- rapid publication on acceptance

- support for research data, including large and complex data types

- gold Open Access which fosters wider collaboration and increased citations

- maximum visibility for your research: over $100 \mathrm{M}$ website views per year

At $\mathrm{BMC}$, research is always in progress. 